\title{
Effect of Aggregate Content on the Concrete Compressive Strength - Ultrasonic Pulse Velocity Relationship
}

\author{
Bayan S. Al-Nu'man ${ }^{1, *}$, Bestoon R. Aziz ${ }^{2}$, Sabr A. Abdulla², Sirwan E. Khaleel ${ }^{2}$ \\ ${ }^{1}$ Professor of civil engineering, Ishik University, Erbil, Iraq \\ ${ }^{2}$ Civil engineer, Hawler Construction Labs, Erbil, Iraq \\ *Corresponding author: bayan.salim@ishik.edu.iq
}

\begin{abstract}
This paper investigates the relationship between the ultrasonic pulse velocity (UPV) and the compressive strength of concrete. The specimens used in the study were made of concrete with varied aggregate contents from 1000 to $1400 \mathrm{~kg} / \mathrm{m}^{3}$. The specimens were made and tested at the Hawler Construction Laboratories (HCLabs) in Erbil, Kurdistan Region of Iraq. The UPV measurement and compressive strength tests were carried out at the concrete age of 28 days. The experimental results show that the relationship between UPV and the compressive strength of concrete is significantly influenced by the coarse aggregate content. Relationships are established for the range of contents of coarse aggregates and discussed.
\end{abstract}

Keywords: concrete strength, NDT, ultrasonic pulse velocity

Cite This Article: Bayan S. Al-Nu'man, Bestoon R. Aziz, Sabr A. Abdulla, and Sirwan E. Khaleel, "Effect of Aggregate Content on the Concrete Compressive Strength - Ultrasonic Pulse Velocity Relationship." American Journal of Civil Engineering and Architecture, vol. 4, no. 1 (2016): 1-5. doi: 10.12691/ajcea-4-1-1.

\section{Introduction}

The ultrasonic pulse velocity (UPV) of concrete to predict compressive strength was under many investigation and research works. [1,2,3,4,5] UPV is influenced by many variables, including mixture proportions, aggregate type, age of concrete, moisture content, and others. [1]

It is found [1] that the factors significantly affecting the concrete strength have little influence on UPV.

Many rules have been presented to describe how the relationship between UPV and the compressive strength of concrete changes with its mixture proportion, however, wide variance is found when applying these rules on practical cases. Therefore, there exists a high uncertainty when one tries to make use of UPV to predict the strength of concrete in different mixture proportions.

Thus, this study tries to establish how significant is the effect of aggregate content on the relationship between UPV and the compressive strength of hardened concrete. This paper uses concrete specimens categorized according to their aggregate content. The UPV measurement and compressive strength tests were carried out at the age of 28 days.

\section{Research Significance}

This paper proposes an approach to establish a clear relationship Formulas / curves between UPV and the compressive strength of concrete based on an influencing factor that is found significant in the strength-UPV relationship.

\section{Experimental Details}

\subsection{Materials}

Materials used for making specimens include cement, fine aggregate (FA), coarse aggregate $\mathrm{CA}$, and with or without high-range water-reducing admixture. The cement used was Portland Type I. River sand with and river coarse aggregate were used as fine and coarse aggregates, respectively. The grading curves for fine and coarse aggregates were all conforming to Iraqi Specification IOS $45[6]$.

The physical and chemical properties of cement used in this work are shown in Table 1 and Table 2, respectively. The grading of fine aggregates and coarse aggregates used are shown in Table 3 and Table 4, respectively.

Table 1. Chemical Compositions and Compounds of Portland Cement, According to ASTM C114-06 \& ASTM C150-07

\begin{tabular}{|c|c|c|}
\hline Oxide & \% by Weight & Limit \\
\hline $\mathrm{SiO}_{2}$ & 20.31 & \\
\hline $\mathrm{CaO}$ & 63.21 & \\
\hline $\mathrm{Al}_{2} \mathrm{O}_{3}$ & 4.48 & \\
\hline $\mathrm{Fe}_{2} \mathrm{O}_{3}$ & 3.31 & $\leq 5 \%$. \\
\hline $\mathrm{MgO}_{\mathrm{SO}_{3}}$ & 1.93 & $\leq 2.8 \%$. \\
\hline $\mathrm{C}_{3} \mathrm{~A}$ & 2.27 & $0.66-1.02$ \\
\hline $\mathrm{L.S.F}$ & 6.28 & \\
\hline $\mathrm{C}_{3} \mathrm{~S}$ & 0.96 & \\
\hline $\mathrm{C}_{2} \mathrm{~S}$ & 61.67 & \\
\hline $\mathrm{C}_{4} \mathrm{AF}$ & 11.92 & $\leq 4 \%$ \\
\hline Loss on ignition & 10.07 & $\leq 1.5 \%$. \\
\hline Insoluble material & 2.48 & \\
\hline & 0.72 & \\
\hline
\end{tabular}


Table 2. Physical Properties of Portland Cement

\begin{tabular}{|c|c|c|c|c|}
\hline \multicolumn{2}{|l|}{ Type of Tests } & Unit & Result & Limit \\
\hline \multirow{2}{*}{$\begin{array}{l}\text { Setting Time by Vicat Needle } \\
\text { ASTM C191-04 \& C187-04 }\end{array}$} & Initial & $\min$ & 150 & $\begin{array}{l}\geq 45 \\
\min \end{array}$ \\
\hline & Final & $\min$ & 210 & $\begin{array}{c}\leq 600 \\
\min \end{array}$ \\
\hline \multicolumn{2}{|c|}{$\begin{array}{l}\text { Soundness Expansion (Le Chatelier) BS } \\
\text { EN 197-01-11 }\end{array}$} & $\mathrm{mm}$ & 2.0 & $\begin{array}{r}\leq 10 \\
\mathrm{~mm}\end{array}$ \\
\hline \multirow{2}{*}{$\begin{array}{c}\text { Compressive Strength } \\
\text { IQS 8-68 \& ASTM C305-06 }\end{array}$} & $\begin{array}{c}3 \\
\text { days }\end{array}$ & $\mathrm{MPa}$ & 37.2 & $\begin{array}{c}\geq 14.7 \\
(150 \\
\left.\mathrm{kg} / \mathrm{cm}^{2}\right)\end{array}$ \\
\hline & $\begin{array}{c}7 \\
\text { days }\end{array}$ & $\mathrm{MPa}$ & 38.4 & $\begin{array}{c}\geq 22.6 \\
(230 \\
\left.\mathrm{kg} / \mathrm{cm}^{2}\right)\end{array}$ \\
\hline \multicolumn{2}{|c|}{$\begin{array}{l}\text { Fineness by air permeability method } \\
\text { ASTM C204-05 }\end{array}$} & $\mathrm{m}^{2} / \mathrm{kg}$ & 300 & $\begin{array}{l}\geq 230 \\
\mathrm{~m}^{2} / \mathrm{kg}\end{array}$ \\
\hline
\end{tabular}

Table 3. Sieve Analysis of Fine Aggregate

\begin{tabular}{|c|c|c|}
\hline sieve No. & \% Pass & Limits of IQS No 45/1984 Zone 2 \\
\hline 10 & 100 & 100 \\
\hline 4.75 & 99 & $90-100$ \\
\hline 2.36 & 88 & $75-100$ \\
\hline 1.18 & 72 & $55-90$ \\
\hline 0.600 & 55 & $35-59$ \\
\hline 0.300 & 29 & $8-30$ \\
\hline 0.150 & 10 & $0-10$ \\
\hline
\end{tabular}

Table 4. Sieve Analysis of coarse Aggregate

\begin{tabular}{|c|c|c|}
\hline Sieve No. & \% Pass & Limits of IQS No 45/1984, Grade (5-40) \\
\hline 75 & 100 & 100 \\
\hline 63 & $/$ & - \\
\hline 37.5 & 100 & $95-100$ \\
\hline 20 & 56 & $35-70$ \\
\hline 14 & $/$ & - \\
\hline 10 & 16 & $10-40$ \\
\hline 5 & 0 & $0-5$ \\
\hline 2.36 & & - \\
\hline
\end{tabular}

\subsection{Specimens}

129 concrete cube specimens were used in this study. Various concrete mix proportions were used all of which were based on ACI 211.1 - Reapproved 2009 [7]. These cubes were categorized according to its aggregate content keeping the paste volume constant (28\%) throughout. The paste volume is calculated knowing the mix proportions of cement (C), water (W), admixture (SP), fine aggregate (FA) and coarse aggregate (CA). Table 5 shows the details of test specimens.

Table 5. Mix proportions of test specimens

\begin{tabular}{|c|c|c|c|c|c|c|}
\hline $\begin{array}{c}\text { No. of } \\
\text { points } *\end{array}$ & $\begin{array}{c}\text { Coarse } \\
\text { aggregate } \\
\mathrm{kg} / \mathrm{m}^{3}\end{array}$ & $\begin{array}{c}\text { Sand } \\
\mathrm{kg} / \\
\mathrm{m}^{3}\end{array}$ & $\begin{array}{c}\mathrm{C} \\
\mathrm{kg} / \\
\mathrm{m}^{3}\end{array}$ & $\begin{array}{c}\text { Water } \\
\mathrm{kg} / \\
\mathrm{m}^{3}\end{array}$ & $\begin{array}{c}\text { Admi } \\
\mathrm{kg} / \\
\mathrm{m}^{3}\end{array}$ & $\begin{array}{c}\text { Paste } \\
\text { Volume } \\
* *\end{array}$ \\
\hline 1 to 13 & 1000 & 840 & 320 & 200 & 4.7 & $28 \%$ \\
\hline 14 to 24 & 1200 & 720 & 340 & 170 & 4.5 & $28 \%$ \\
\hline 25 to 32 & 1300 & 640 & 300 & 190 & 0 & $28 \%$ \\
\hline 33 to 43 & 1400 & 520 & 310 & 185 & 0 & $28 \%$ \\
\hline
\end{tabular}

* Each point is the average of three results (129 cubes).

** Paste Volume $\%=\frac{V_{w}+V_{S p}+V_{c}}{V_{w}+V_{s p}+V_{c}+V_{C A}} * 100$

All the specimens were cast in steel cube molds (150 $\mathrm{mm}$ ) and kept in their molds for approximately 24 hours in the laboratory. After removing the molds, concrete cubes were cured in water at $20^{\circ} \mathrm{C}$ and tested at age of 28 days. At each test, the ultrasonic pulse velocity and compressive strength of three saturated surface dry SSD specimens were measured according to the specification of ASTM C 597 and ASTM C 39, respectively.

\subsection{Equipment}

The principle of ultrasonic pulse velocity measurement involves sending a wave pulse into concrete and measuring the travel time for the pulse to propagate through the concrete. The pulse is generated by a transmitter and received by a receiver.

As illustrated in Figure 1, ultrasonic pulse velocities were measured by a commercially available pulse meter with an associated transducer pair through a direct transmission mode. The transducer pair had a nominal frequency of $54 \mathrm{kHz}$.

In the experimental work, the transmitter and receiver were placed at the top and bottom surfaces of a cube specimen, in parallel direction to the destructive load.

Knowing the path length $(L)$, the measured travel time $(t)$ can be used to calculate the pulse velocity $(v)$ as follows

$$
v=L / t
$$

where $L$ is the travel path length of ultrasound in the cube. The concrete surface must be prepared in advance for a proper coupling agent. Firm contact of the transducers against the concrete surface is needed.

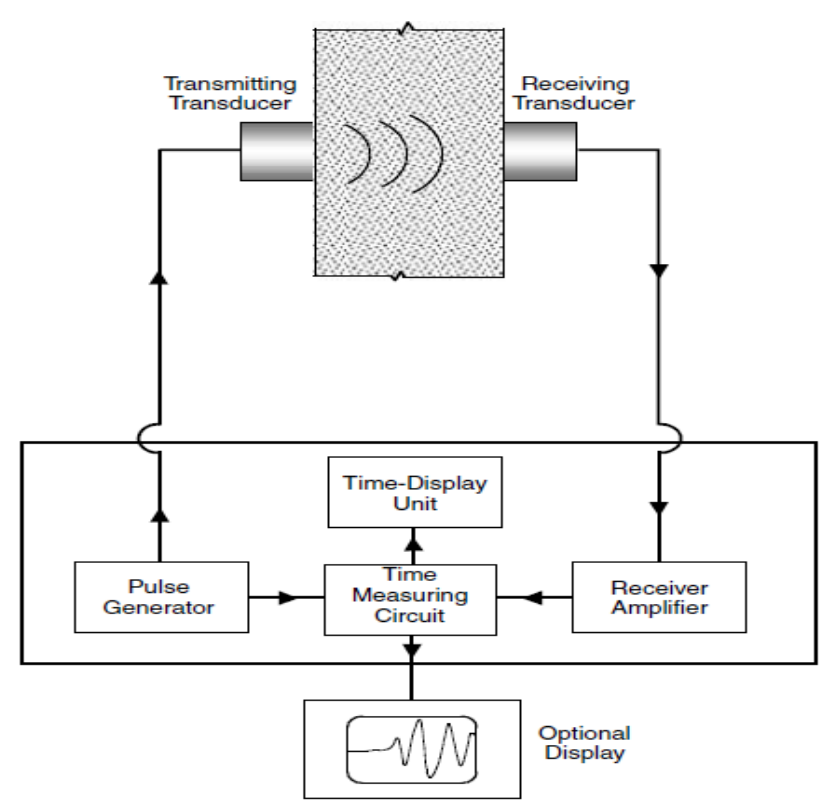

Figure 1. Schematic diagram of pulse velocity test circuit. [8]

Direct velocity measurements were taken as the average of 10 readings for each cube tested. The direct path length for these measurements was through the cube thickness of $150 \mathrm{~mm}$. Direct UPV was calculated as the ratio of the path length to the time of flight.

\section{Relationship between UPV and 28-day strength of concrete cubes}

Figure 2 shows the relationship between UPV and strength at the age of 28 days of concrete having mixture proportions, as listed in Table 1, for a total of 13 data points (each data point is the average of three results) for a coarse aggregate content of $1000 \mathrm{~kg} / \mathrm{m}^{3}$. A relationship curve is drawn by exponential regression of all data points and its coefficient of determination $R^{2}$ equals 0.8232 , as shown in Figure 2. 


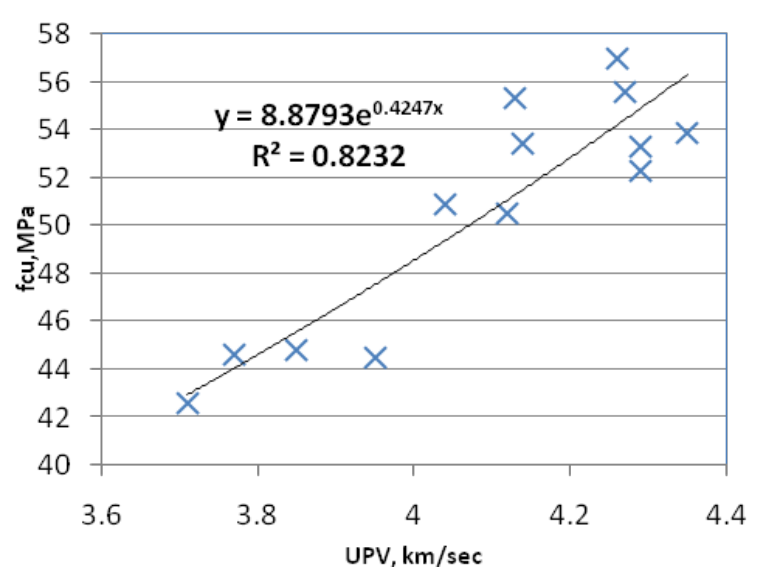

Figure 2. Compressive strength - UPV relationship for $1000 \mathrm{~kg} / \mathrm{m} 3$ aggregate content

Figure 3, Figure 4 and Figure 5 show, respectively, the relationship between UPV and strength at the age of 28 days of concrete having mixture proportions, as listed in Table 1, for a total of 11, 8 and 11 data points (each data point is the average of three results) for coarse aggregate contents of 1200,1300 and $1400 \mathrm{~kg} / \mathrm{m}^{3}$, respectively. Relationship curves are drawn by exponential regression of corresponding data points and its coefficient of determination $R^{2}$ equals $0.8703,0.8801$ and 0.8436 , as shown in Figure 3, Figure 4 and Figure 5, respectively.

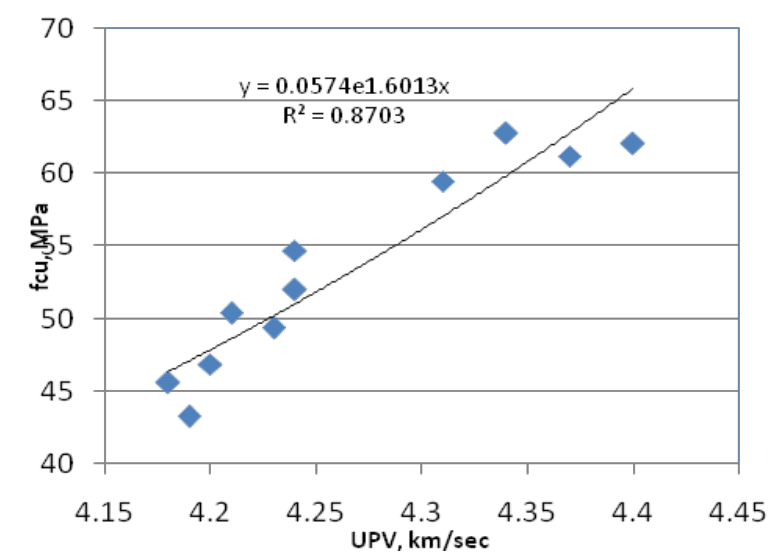

Figure 3. Compressive strength - UPV relationship for $1200 \mathrm{~kg} / \mathrm{m}^{3}$ aggregate content

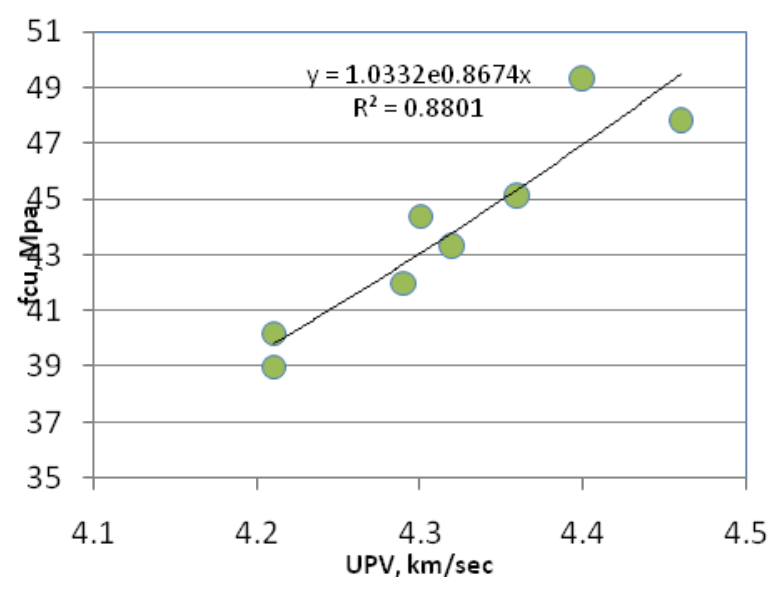

Figure 4. Compressive strength - UPV relationship for $1300 \mathrm{~kg} / \mathrm{m}^{3}$ aggregate content

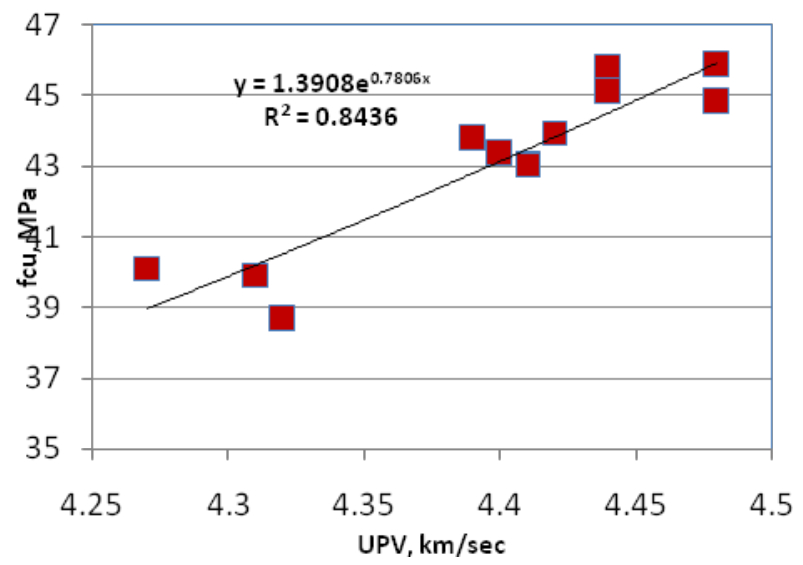

Figure 5. Compressive strength - UPV relationship for $1400 \mathrm{~kg} / \mathrm{m}^{3}$ aggregate content

Figure 6 puts together the four relationships between UPV and strength at the age of 28 days of concrete having mixture proportions, as listed in Table 1 , for a total of 43 data points (each data point is the average of three results) for coarse aggregate contents of 1000, 1200, 1300 and $1400 \mathrm{~kg} / \mathrm{m}^{3}$. The relationship curves are drawn by exponential regression, as shown in Figure 6.

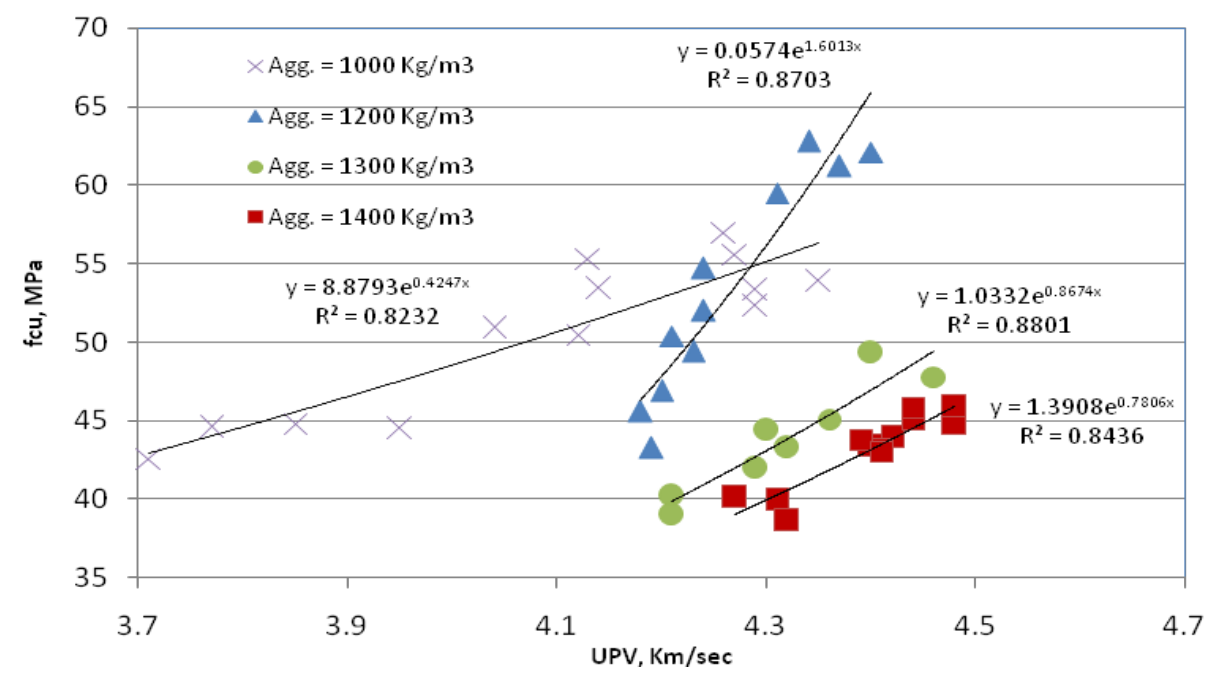

Figure 6. Compressive strength - UPV relationships for different aggregate contents 
Figure 6 shows that for a given coarse aggregate content a particular UPV-strength relationship can be drawn. In this work, four relationships are established as follows:

$$
\begin{aligned}
& f_{c u}=8.8793 \exp (0.4247 v) \text { for CA }=1000 \mathrm{~kg} / \mathrm{m}^{3} \\
& f_{c u}=0.0574 \exp (1.6013 v) \text { for } \mathrm{CA}=1200 \mathrm{~kg} / \mathrm{m}^{3} \\
& f_{c u}=1.0332 \exp (0.8674 v) \text { for } \mathrm{CA}=1300 \mathrm{~kg} / \mathrm{m}^{3} \\
& f_{c u}=1.3908 \exp (0.7806 \mathrm{v}) \text { for } \mathrm{CA}=1400 \mathrm{~kg} / \mathrm{m}^{3}
\end{aligned}
$$

where $f_{c u}$ and $v$ represent the cube compressive strength (MPa) and the UPV $(\mathrm{km} / \mathrm{s})$, respectively.

These relationship curves represent the local tested concrete with CA content ranging between 1000 to 1400 $\mathrm{kg} / \mathrm{m}^{3}$, that is, additional work is required to cover the wide range of coarse aggregate contents.

To improve the UPV-strength relationship of hardened concrete, it is required to study wide range of results verified statistically, and this is now under investigation of the authors.

\section{Comparison with a companion work}

Figure 7 shows the data points of UPV and strength at the age of 28 days of concrete cubes received by the Hawler Construction Laboratories (HCLabs) from various construction projects in Erbil, Kurdistan Region of Iraq during the last half of 2014 and tested at age of 28 days [9]. The 4 equations developed herein are shown on the graph also.

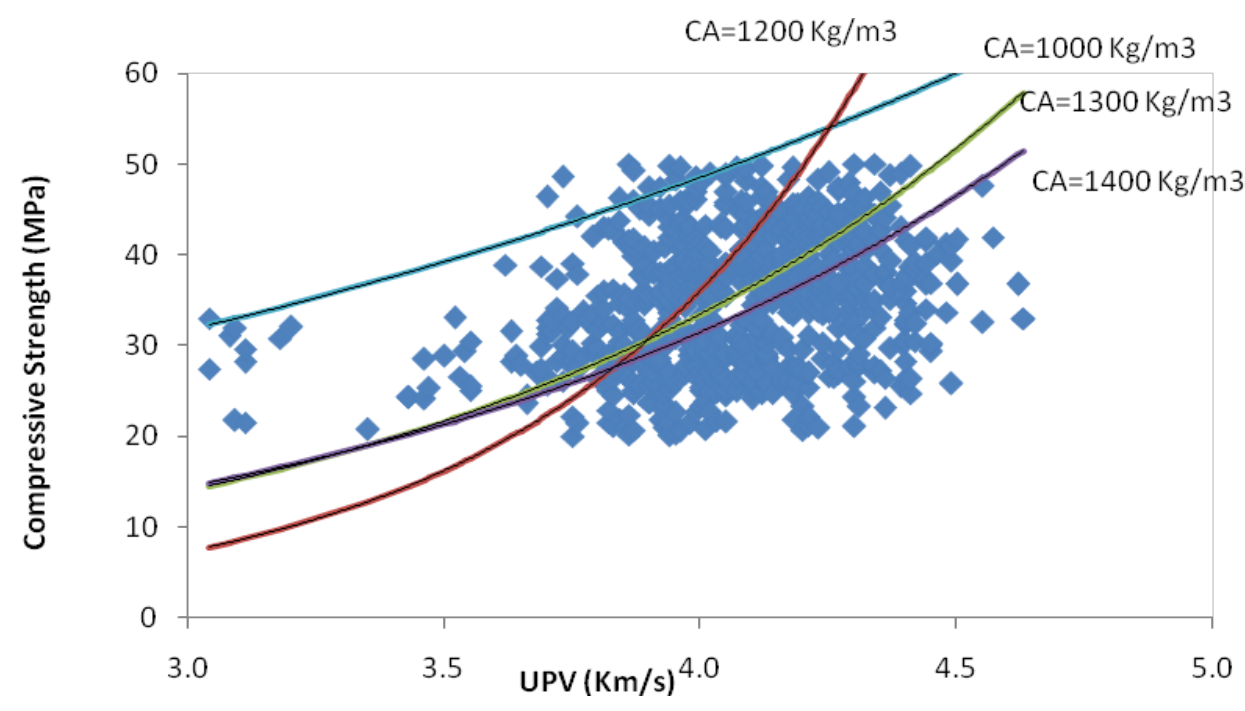

Figure 7. Cube Compressive Strength - UPV measurements at HCLabs (Ref. 9) and current equations

Because of the scattered distribution of data points, a noticeable error may occur if one estimates the strength of concrete by using a single relationship curve with a UPV value.

Figure 7 shows that using the current 4 equations may estimate, by a better way, the compressive strengths from the UPV readings. Considering the influence of coarse aggregate content of concrete specimens on the UPVstrength relationship of hardened concrete makes the approach more rational.

The new approach treats the coarse aggregate content as a ruling factor in establishing the UPV-strength relationship of hardened concrete based on the fact that, for a particular coarse aggregate content, both UPV and strength of concrete are proportional to the density of hardened concrete.

\section{Conclusions}

This work intends to establish UPV-strength relationship of hardened concrete based on an influencing factor, the coarse aggregate content, and the following conclusions may be drawn:

1. It is found that when the volume of cement paste is constant, the coarse aggregate content is significant in establishing the UPV-strength relationship of hardened concrete.

2. For a particular CA content, an independent UPVstrength relationship can be set.

3. The super-plasticizer is effective in increasing the UPV-strength relationship values by a certain margin over control specimens. This finding requires further research.

4. In this work four relationship curves are established representing the local tested concrete with CA content ranging between 1000 to $1400 \mathrm{~kg} / \mathrm{m}^{3}$.

5. In comparison with large number of field data [9], the approach seems more rational

\section{Acknowledgement}

The authors would like to express their gratitude to Mr. Nazar H. Smail, Director of the Hawler Construction Labs HCLabs, Erbil, Iraq, and his staff for their support rendered in this study.

\section{References}

[1] Lin,Y., Kuo, S-F, Hsiao C., Lai, C-P "Investigation of Pulse Velocity- Strength Relationship of hardened Concrete" ACI Materials Journal, V. 104, No. 4, July.-Aug. 2007 , pp. 344-350. 
[2] Tanigawa, Y.; Baba, K.; and Mori, H., "Estimation of Concrete Strength by Combined Nondestructive Testing Method," In-Situ/ Nondestructive Testing of Concrete, SP-82, V. M. Malhotra, ed., American Concrete Institute, Farmington Hills, Mich., 1984, pp. 57-76.

[3] Sturrup, V. R.; Vecchio, F. J.; and Caratin, H., "Pulse Velocity as a Measure of Concrete Compressive Strength," InSitu/Nondestructive Testing of Concrete, SP-82, V. M. Malhotra, ed., American Concrete Institute, Farmington Hills, Mich., 1984, pp. 201-227.

[4] Lin, Y.; Changfan, H.; and Hsiao, C., "Estimation of HighPerformance Concrete Strength by Pulse Velocity,” Journal of the Chinese Institute of Engineers, V. 20, No. 6, 1998, pp. 661-668.

[5] Lin, Y.; Lai, C. P.; and Yen, T., "Prediction of Ultrasonic Pulse Velocity (UPV) in Concrete," ACI Materials Journal, V. 100, No. 1, Jan.-Feb. 2003, pp. 21-28.
[6] Iraqi Specification IOS 45-1984.

[7] ACI 211.1 - Reapproved 2009, Standard Practice for Selecting Proportions for Normal, Heavyweight, and Mass Concrete, an ACI Standard Reported by ACI Committee 211, 38pp.

[8] Tarun R. Naik, V. Mohan Malhotra and John S. Popovics, "The Ultrasonic Pulse Velocity Method" in the Handbook of Nondestructive Testing of Concrete, Chapter 8, 2004.

[9] Bayan S. Al-Nu'man, Bestoon R. Aziz, Sabr A. Abdulla, and Sirwan E. Khaleel, "Compressive Strength Formula for Concrete using Ultrasonic Pulse Velocity", International Journal of Engineering Trends and Technology (IJETT) - Volume 26 Number 1- August 2015, pp. 9-13. 